\title{
Comparison of the efficacy and safety of retroperitoneal laparoscopic and open surgery for the correction of retrocaval ureter
}

This article was published in the following Dove Press journal:

Therapeutics and Clinical Risk Management

6 June 2017

Number of times this article has been viewed

\author{
Lijun Mao ${ }^{1,2}$ \\ Kai Xu' \\ Meng Ding' \\ Jun $\operatorname{Pan}^{\prime}$ \\ Zhicheng Guo' \\ 'Department of Urinary Surgery, The \\ Affiliated Hospital of Xuzhou Medical \\ University, ${ }^{2}$ Clinical College, Xuzhou \\ Medical University, Xuzhou, People's \\ Republic of China
}

Correspondence: Lijun Mao Department of Urinary Surgery, The Affiliated Hospital of Xuzhou Medical College, Xuzhou 221002, People's Republic of China Emailmljmlj05@I26.com
Objective: The aim of this study was to compare the clinical efficacy and safety of retroperitoneal laparoscopic and open surgery for the correction of retrocaval ureter.

Patients and methods: Clinical data of 14 patients with retrocaval ureter were analyzed retrospectively. Among them, nine were treated by open surgical therapy and five by retroperitoneal laparoscopic surgery. The ureter was transpositioned to a normal anatomic position followed by laparoscopic intracorporeal uretero and ureteric anastomosis.

Results: Open surgery was successfully performed in nine cases. The mean surgery time was $95.6 \pm 22.0 \mathrm{~min}$, and blood loss was $108.6 \pm 34.5 \mathrm{~mL}$. The mean hospitalization time was $14.8 \pm 1.1$ days, and the recovery time was $52.8 \pm 1.3$ days. Retroperitoneal laparoscopic surgery was successfully performed in five cases without conversion to open surgery and without severe perioperative complications. The mean surgery time was $112.0 \pm 42.1 \mathrm{~min}$, and blood loss was $45.3 \pm 15.1 \mathrm{~mL}$. The mean hospitalization time was $7.3 \pm 1.9$ days, and the recovery time was 23.6 \pm 2.4 days. Postoperative urine leakage occurred in one patient. No postoperative ureter stenosis occurred in patients who were treated by retroperitoneal laparoscopic surgery.

Conclusion: Retroperitoneal laparoscopic ureteroplasty in patients with retrocaval ureter is safe and effective with less trauma and faster recovery and could be used as first choice for the treatment of retrocaval ureter.

Keywords: retrocaval ureter, laparoscopy, open surgery

\section{Introduction}

The incidence of retrocaval ureters is approximately 1:1,000 in general population, with males having a three- to fourfold predominance. Retrocaval ureter is typically a silent disease until the third or fourth decade of life. However, Sun et $\mathrm{al}^{1}$ retrospectively analyzed the clinical data of eight patients with retrocaval ureter and found that the mean age of the patients was 9.2 years (range 2-13 years). The condition is most commonly right-sided with a left-sided lesion most often associated with situs inversus or caval duplication. The presence of retrocaval ureter on the left side is a very rare finding and has important clinical and surgical implications. If the subcardinal vein persists at a left vena cava system, a left preureteral vena cava is encountered. Kozyrakis et $\mathrm{al}^{2}$ reported a case of left retrocaval ureter associated with urothelial malignancy without situs inversus.

Various techniques for the management of retrocaval ureter have been reported, including open surgery, retroperitoneoscopic surgery and pure robotic retrocaval ureter repair. Open surgery has been the traditional treatment and is usually successful; however, it requires a long skin incision and causes significant postoperative pain 
with a prolonged convalescence. Recently, laparoscopy has been established as the standard approach for many urological procedures. From May 2001 to October 2014, we used open surgery and retroperitoneal laparoscopic surgery for the treatment of 14 cases of retrocaval ureter in our hospital. We compared the efficacy and safety of retroperitoneal laparoscopic and open surgery for the correction of retrocaval ureter.

\section{Patients and methods Subjects}

From May 2001 to October 2014, 14 cases with retrocaval ureter were enrolled, including 11 males and three females. The age ranged from 17 to 40 years, and the mean was 33.0 years. The course of the disease ranged from 1 to 24 months. The main clinical manifestation included 13 cases of repetitive right lumbago pain, one case of urolithiasis and three cases of intermittent hematuria. Hydronephrosis was found in four cases by physical examination. All patients had no surgical treatment of right kidney or ureter. This study was approved by the ethics committee of the Affiliated Hospital of Xuzhou Medical College, and all the patients provided informed consent.

\section{Diagnostic methods}

All the 14 cases were examined by B-ultrasound, plain abdominal radiograph and intravenous pyelography. Among them, nine were retrograde pyelography, five were multilayer scan computed tomography (CT) urography with threedimensional (3D) display. B-ultrasound showed that all the 14 cases were expansionary in different degrees on the right renal calyces, pelvis and superior ureter. Intravenous urography (IVU) showed that nine cases were moderate hydronephrosis and four cases were severe hydronephrosis.
Imaging examination showed that the right ureter displaced to the median line before the third to fourth lumbar and was circuitous as typical "S" or "J" type. It passed over the median line after the vena cava and then moved across the front of inferior vena cava (IVC). A typical displacement feature of retrocaval ureter is shown in Figure 1.

\section{Open surgery}

Open surgery was performed in nine cases. After general anesthesia, the cutoff of ureter was above $1 \mathrm{~cm}$ at the turning point of superior ureter (the proximate of obstruction), and retrocaval ureter was repositioned to the lateral of vena cava. In the case of no tension, end-to-end anastomosis was made with a 5-0 absorbable thread after the placement of double $J$ tube. The surgical area was flushed and checked for no bleeding, a drainage tube was placed at the retroperitoneal space and the double J tube was removed with cystoscope after 1 month.

\section{Retroperitoneal laparoscopic surgery}

Retroperitoneal laparoscopic surgery was performed in five cases. After general anesthesia, small incisions were made in the skin, under the 12th costal margin of posterior axillary line, at the 12th costal tip of anterior axillary line and two fingers above the iliac crest of midaxillary line, the $10 \mathrm{~mm}$ casing was punctured (Figure 2), visual retroperitoneal dilator was inserted into the retroperitoneal space and dilated to expand the operative space for $5 \mathrm{~min}$, then artificial pneumoperitoneum was set up by filling $\mathrm{CO}_{2}$, and the pressure was between 1.33 and $2.0 \mathrm{kPa}$. The laparoscope was inserted into the puncture point of iliac crest; perirenal fascia and adipose capsule were incised; renal pelvis and superior ureter were exposed; ureter and IVC were freed; the anatomical relationship was defined and then inferior ureter and retrocaval ureter were freed. The distal part of the dilated renal pelvis was
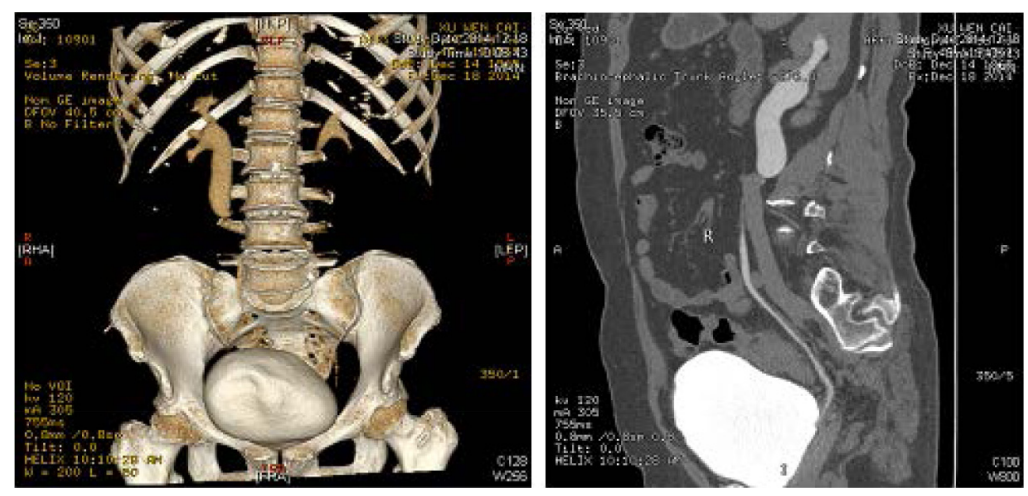

Figure I CTU revealed hydronephrosis and dilatation of the right proximal ureter. Note: The ureter was found to be coursing medially posterior to the IVC.

Abbreviations: CTU, computed tomography urography; IVC, inferior vena cava. 


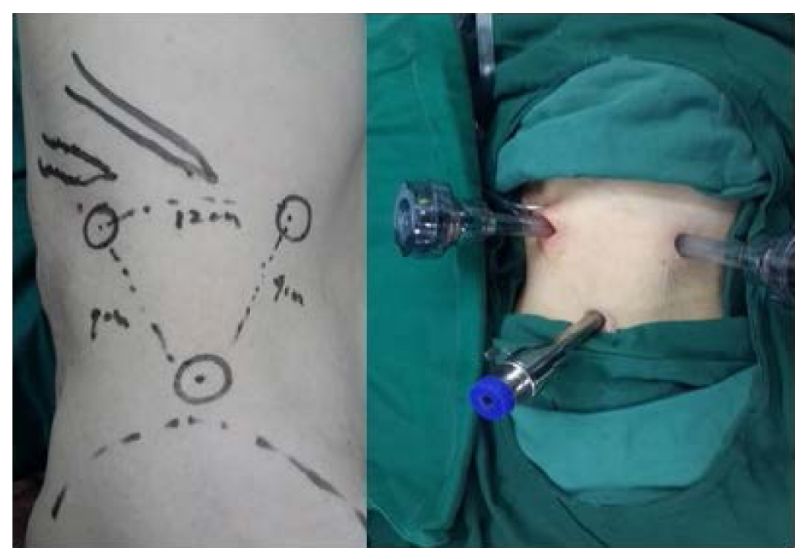

Figure 2 Port placement in retroperitoneal laparoscopic surgery in our center.

transected. The ureter was separated from the IVC and repositioned anterolaterally to it. The anterior wall of the ureter was sutured discontinuously with a 5-0 absorbable threads, the double $\mathrm{J}$ tube was inserted under laparoscopy and then the opposite side was sutured continuously (Figure 3).

\section{Results Open surgery}

The open surgery was successfully performed in nine cases, and the mean surgery time was $95.6 \pm 22.0 \mathrm{~min}$ (range 60-130 min). The mean blood loss in the surgery was $106.7 \pm 32.2 \mathrm{~mL}$ (range $50-160 \mathrm{~min}$ ). The mean hospitalization time was $15.3 \pm 1.2$ days (range 14-17 days), and the recovery time was $52.8 \pm 1.3$ days (range $45-56$ days). Postoperative follow-up ranged from 5 months to 3 years (mean 14 months). The symptoms disappeared, hydronephrosis disappeared or reduced and no postoperative complications occurred.

\section{Retroperitoneal laparoscopic surgery}

The retroperitoneal laparoscopic surgery was successfully performed in five cases without conversion to open surgery. The mean surgery time was $112.0 \pm 42.1 \mathrm{~min}$ (range 70-180 $\mathrm{min}$ ), and the blood loss during the surgery was $50.0 \pm 17.0 \mathrm{~mL}$ (range 30-70 min). The mean hospitalization
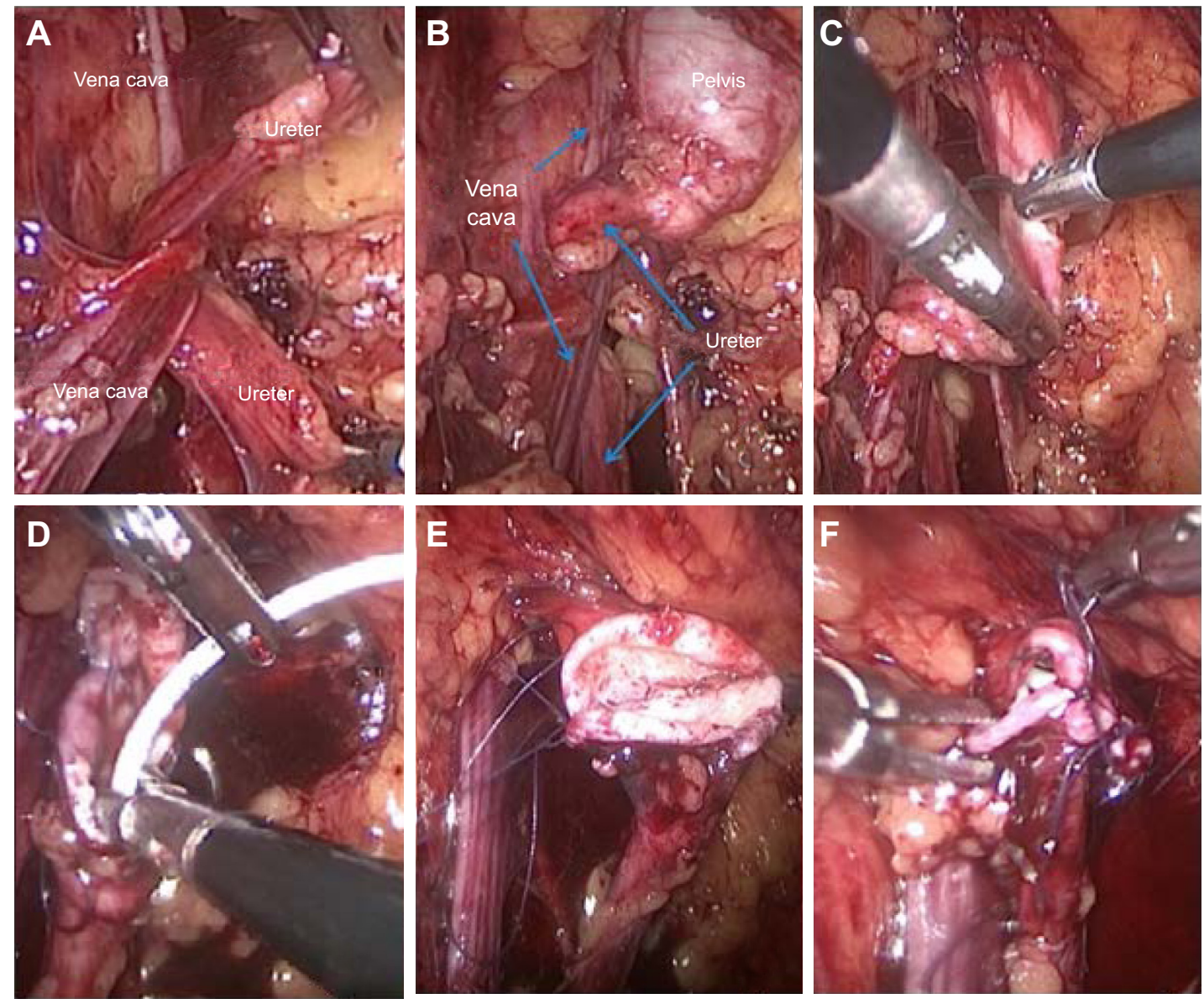

Figure 3 Procedures of retroperitoneal laparoscopy.

Notes: (A, B) Anatomic relationship between vena cava and ureter under retroperitoneal laparoscopy. (C) Transection of the distal dilated part of the renal pelvis and the preservation of the retrocaval segment. (D) A double-J stent was laparoscopically inserted in an antegrade manner. (E) The anterior wall of the ureter was sutured discontinuously. (F) The opposite side was sutured continuously. 
Table I Clinical data of the patients

\begin{tabular}{|c|c|c|c|}
\hline Parameter & Open surgery & $\begin{array}{l}\text { Retroperitoneal } \\
\text { laparoscopy }\end{array}$ & $P$-value \\
\hline Age (year) (range) & $34.4 \pm 9.2(17-40)$ & $30.4 \pm 5.6(32-36)$ & $<0.05$ \\
\hline Gender (n) & 9 & 6 & \\
\hline Male & 7 & 5 & \\
\hline Female & 2 & I & \\
\hline Operative time (min) & $95.6 \pm 22.0$ & $112.0 \pm 42.1$ & $<0.05$ \\
\hline $\begin{array}{l}\text { Intraoperative blood } \\
\text { loss }(\mathrm{mL})\end{array}$ & $106.7 \pm 32.2$ & $50.0 \pm 17.0$ & $<0.05$ \\
\hline $\begin{array}{l}\text { Postoperative urine } \\
\text { leakage }\end{array}$ & $0 / 9$ & $1 / 5$ & $<0.05$ \\
\hline Hospital stay (day) & $15.3 \pm 1.2$ & $7.4 \pm 1.1$ & $<0.05$ \\
\hline Recovery time (day) & $52.8 \pm 1.3$ & $23.6 \pm 2.4$ & $<0.05$ \\
\hline
\end{tabular}

Note: Data are presented as mean \pm standard deviation.

time was $7.4 \pm 1.1$ days (range 6-9 days), and the recovery time was 23.6 \pm 2.4 days (range 16-32 days). Postoperative follow-up ranged from 6 months to 2 years (mean 11 months). Postoperative examination by B-ultrasound showed that hydronephrosis and superior ureteral expansion were significantly reduced, and no postoperative stoma stenosis or other complications occurred (Table 1).

\section{Discussion}

Retrocaval ureter is a rare embryological venous malformation resulting in dorsal displacement of the ureter to the caudal vena cava. Two types of retrocaval ureter are described: type I (low loop; 90\% of cases) results in a "fishhook" or "s" shape appearance of the middle segment of the ureter where $50 \%$ develop hydronephrosis and type II (high loop) the ureter crosses the cava at the ureteropelvic junction (UPJ), resulting in minimal to no dilation. An isolated left retrocaval ureter with single left-sided IVC is very rare and only four cases have been reported in the literature. Thirugnanasambandam et $\mathrm{al}^{3}$ reported a case of isolated left retrocaval ureter with a single left-sided IVC without situs inversus.

Open surgery is the classic treatment for retrocaval ureter, but it requires a large skin incision and causes significant postoperative pain with a prolonged convalescence. Consequently, minimally invasive surgical management has emerged as the method of choice for retrocaval ureter. Laparoscopy is currently a major procedure to treat many urological diseases. Variations in the reported laparoscopic techniques include transperitoneal laparoscopic repair, retroperitoneal laparoscopic repair and single-port laparoscopic repair, and each one has its own advantages and limitations.

Many surgeons prefer transperitoneal approach due to larger working space and better orientation via familiar anatomical landmark. El Harrech et $\mathrm{al}^{4}$ described the experience on three cases about transperitoneal laparoscopic pyelopyelostomy for retrocaval ureter without the excision of retrocaval segment. Ding et $a l^{5}$ performed transperitoneal laparoscopic pyelopyelostomy or ureteroureterostomy in nine patients with retrocaval ureter.

Retroperitoneal approach enables direct access to the kidney and does not require mobilization of the bowel and other organs around the kidney and ureter, which possibly reduces the incidence of complications. Mugiya et $\mathrm{al}^{6}$ provided the first report of retroperitoneoscopic intracorporeal ureteral anastomosis using an automatic suture device to correct retrocaval ureter, where the operating time was decreased. Recently, Liu et $\mathrm{al}^{7}$ reported the experience of retroperitoneal laparoscopic ureteroplasty on nine cases of retrocaval ureter and suggested it as the first-line treatment for retrocaval ureter because of its advantages of minimal invasion and shorter hospital stay. Skilled laparoscopic anastomosis with a retroperitoneal approach can shorten operative duration.

Laparoscopic ureteric reconstruction depends on several ports. Recently, laparoendoscopic single-site surgery (LESS) has been used to improve the cosmetic outcome and further reduce morbidity. Abdel-Karim et $\mathrm{al}^{8}$ described a case of a morbidly obese female with retrocaval ureter treated with LESS. Kumar et $\mathrm{al}^{9}$ performed single-incision multiport laparoendoscopy to repair retrocaval ureter using the Santosh Postgraduate Institute (PGI) ureteric tacking fixation technique which makes suture easily and rapidly by conventional laparoscopic instruments. In addition, Chen et a ${ }^{10}$ described a case of retrocaval ureter associated with ureteral calculus, which was managed by retroperitoneal LESS ureterolithotomy and ureteroureterostomy. Similarly, Kang et $\mathrm{al}^{11}$ performed LESS pyelopyelostomy for retrocaval ureter in four patients. The single-port device was made with a surgical glove and Foley catheter and allowed the introduction of three trocars. However, Rebouças et al ${ }^{12}$ described a case of retrocaval ureter treated with LESS without using any special devices such as single-port or bended instruments. Overall, LESS might represent a feasible new treatment option for retrocaval ureter.

Although symptoms such as renal colic, sustained hematuria or the progression of extent of hydroureteronephrosis may indicate the need for early surgical intervention, functionally unobstructed and asymptomatic retrocaval ureters that show hydronephrosis on anatomical imaging may not demand immediate surgery. Yen et $\mathrm{al}^{13}$ suggested that immediate surgical repair is not always needed because they reported conservative management of two cases of retrocaval ureter with significant proximal hydroureteronephrosis. 
In this study, we performed retroperitoneoscopic ureteroplasty for five cases of retrocaval ureter. We summarized our experience as follows: 1) preservation of the retrocaval segment facilitated the repair and shortened operative time with good outcome and without symptoms. 2) A double-J stent was laparoscopically inserted in an antegrade manner. The stent was removed 4-6 weeks postoperatively. 3) The ureter was transected just $1 \mathrm{~cm}$ above the retrocavel segment to avoid anastomotic stenosis. The anterior wall of the ureter was sutured discontinuously, and then the opposite side was sutured continuously to reduce urinous infiltration.

Our study has several limitations. First, the sample size is small. We enrolled only 14 patients. Second, the follow-up is short, which is only 2 years. Further studies with large sample size and long follow-up will help confirm our conclusion.

\section{Conclusion}

Retroperitoneal laparoscopic ureteroplasty is a safe, an effective and a minimally invasive surgical alternative for the management of retrocaval ureter, and could be used as the first choice for the treatment of retrocaval ureter.

\section{Acknowledgment}

This study was supported by grants from Jiangsu Province Science Foundation of China (No BK2007032), the Project of Invigorating Health Care through Science, Technology and Education and Jiangsu Provincial Medical Youth Talent.

\section{Disclosure}

The authors report no conflicts of interest in this work.

\section{References}

1. Sun JS, Zhang G, Lin T. Retrocaval ureter in children: a report of eight cases. West Indian Med J. 2015;64(4):397-399.

2. Kozyrakis D, Prombonas I, Kyrikos V, Grigorakis A, Pliotas G, Malovrouvas D. Left retrocaval ureter associated with urothelial malignancy: presentation of a rare case. Urol J. 2012;9(2):527-529.

3. Thirugnanasambandam V, Nayak P, Mossadeq A. Left retrocaval ureter without situs inversus or inferior venacava duplication. Indian J Urol. 2015;31(4):372-373.

4. El Harrech Y, Ghoundale O, Kasmaoui EH, Touiti D. Transperitoneal laparoscopic pyelopyelostomy for retrocaval ureter without excision of the retrocaval segment: experience on three cases. Adv Urol. 2016; 2016:5709134.

5. Ding GQ, Xu LW, Li XD, et al. Pure transperitoneal laparoscopic correction of retrocaval ureter. Chin Med J (Engl). 2012;125(13): 2382-2385.

6. Mugiya S, Suzuki K, Ohhira T, Un-No T, Takayama T, Fujita K. Retroperitoneoscopic treatment of a retrocaval ureter. Int J Urol. 1999; 6(8):419-422.

7. Liu E, Sun X, Guo H, et al. Retroperitoneoscopic ureteroplasty for retrocaval ureter: report of nine cases and literature review. Scand $J$ Urol. 2016;50(4):319-322.

8. Abdel-Karim AM, Yahia E, Hassouna M, Missiry M. Laparoscopic single site surgery for repair of retrocaval ureter in a morbidly obese patient. Urol Case Rep. 2015;4:61-63.

9. Kumar S, Shankaregowda SA, Devana SK, Jain S, Singh SK. Singleincision multiport laparoendoscopic technique to repair retrocaval ureter using the Santosh PGI ureteric tacking fixation technique. Asian J Endosc Surg. 2014;7(4):337-341.

10. Chen Z, Chen X, Luo YC, et al. Retroperitoneal laparoendoscopic single-site ureterolithotomy and ureteroureterostomy for retrocaval ureter with ureteral calculus: first case report. Scand J Urol Nephrol. 2012;46(6):437-440.

11. Kang N, Zhang JH, Niu YN, et al. Retroperitoneal laparoendoscopic single-site surgery for the treatment of retrocaval ureter. World J Urol. 2013;31(1):205-211.

12. Rebouças RB, Monteiro RC, Medeiros PF Jr, et al. Laparoendoscopic single-site repair of retrocaval ureter without any special devices. Int Braz J Urol. 2013;39(1):141-142.

13. Yen JM, Lee LS, Cheng CW. Conservative management of retrocaval ureter: a case series. Int J Surg Case Rep. 2015;15:93-95.
Therapeutics and Clinical Risk Management

\section{Publish your work in this journal}

Therapeutics and Clinical Risk Management is an international, peerreviewed journal of clinical therapeutics and risk management, focusing on concise rapid reporting of clinical studies in all therapeutic areas, outcomes, safety, and programs for the effective, safe, and sustained use of medicines. This journal is indexed on PubMed Central, CAS,

\section{Dovepress}

EMBase, Scopus and the Elsevier Bibliographic databases. The manuscript management system is completely online and includes a very quick and fair peer-review system, which is all easy to use. Visit http://www.dovepress.com/testimonials.php to read real quotes from published authors. 